\title{
Quality Assurance Project Plan for the HWMA/RCRA Closure Certification of the TRA-731 Caustic and Acid Storage Tank System
}

\section{Notice of Violation Consent Order}

S. K. Evans

January 2002

Idaho National Engineering and Environmental Laboratory Bechtel BWXT Idaho, LLC 


\title{
Quality Assurance Project Plan for the HWMA/RCRA Closure Certification of the TRA-731 Caustic and Acid Storage Tank System
}

\section{Notice of Violation Consent Order}

\author{
Susan K. Evans
}

January 2002

Idaho National Engineering and Environmental Laboratory Idaho Falls, Idaho 83415

Prepared for the

U.S. Department of Energy

Assistant Secretary for Environmental Management

Under DOE Idaho Operations Office

Contract DE-AC07-99ID13727 


\begin{abstract}
This Quality Assurance Project Plan for the HWMA/RCRA Closure Certification of the TRA-731 Caustic and Acid Storage Tank System is one of two documents that comprise the Sampling and Analysis Plan for the HWMA/RCRA closure certification of the TRA-731 caustic and acid storage tank system at the Idaho National Engineering and Environmental Laboratory. This plan, which provides information about the project description, project organization, and quality assurance and quality control procedures, is to be used in conjunction with the Field Sampling Plan for the HWMA/RCRA Closure Certification of the TRA-731 Caustic and Acid Storage Tank System. This Quality Assurance Project Plan specifies the procedures for obtaining the data of known quality required by the closure activities for the TRA-731 caustic and acid storage tank system.
\end{abstract}




\section{CONTENTS}

ABSTRACT

ACRONYMS ix

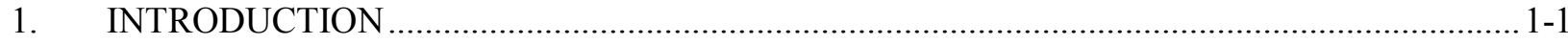

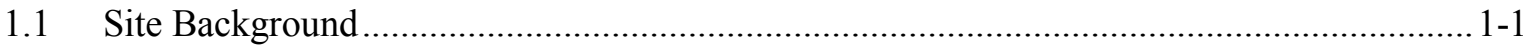

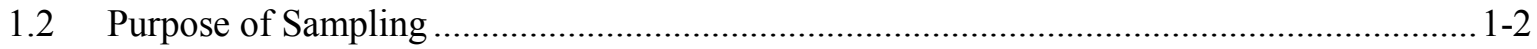

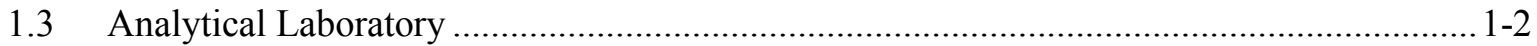

2. PROJECT ORGANIZATION AND RESPONSIBILITIES …...............................................

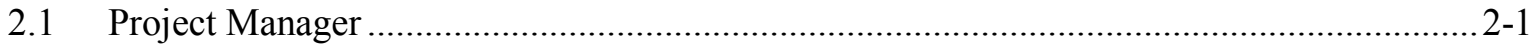

2.2 Sampling and Data Quality Personnel …................................................................... 2-2

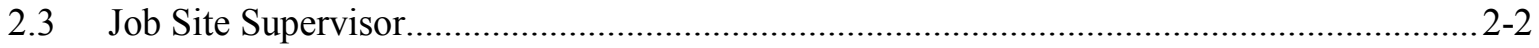

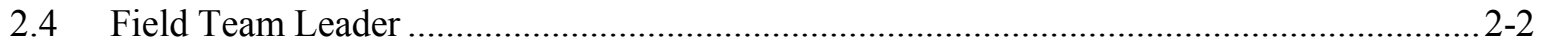

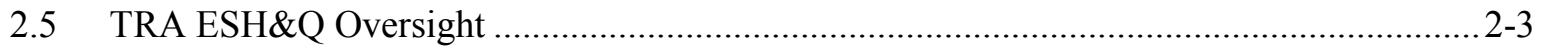

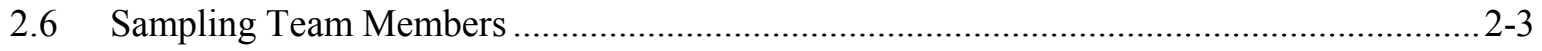

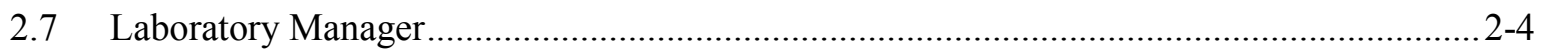

2.8 Laboratory Quality Assurance Officer................................................................... 2-4

2.9 Laboratory Sample Custodian and Record Coordinator ............................................. 2-4

3. QUALITY OBJECTIVES AND CRITERIA FOR MEASUREMENT DATA........................... 3-1

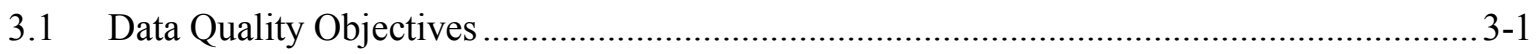

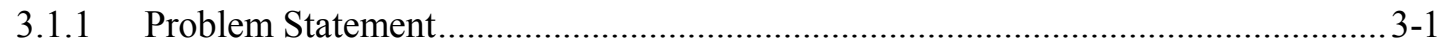

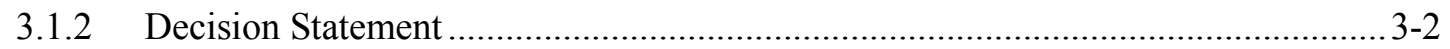

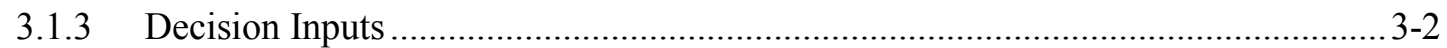

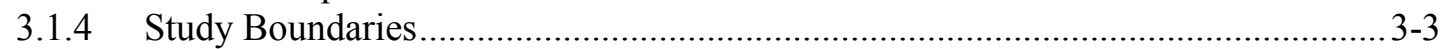

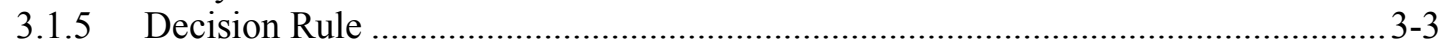

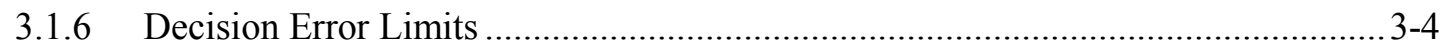

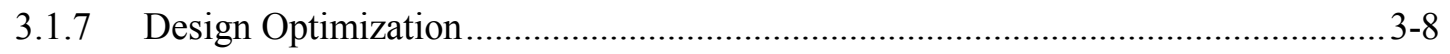

3.2 Measurement Performance Criteria ...........................................................................

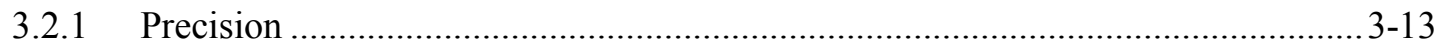

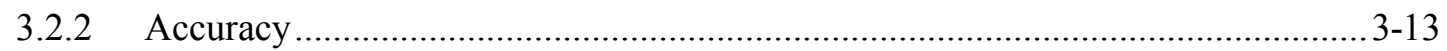

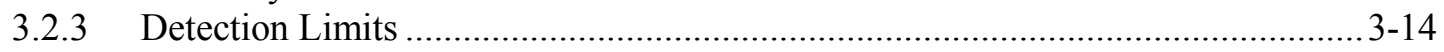

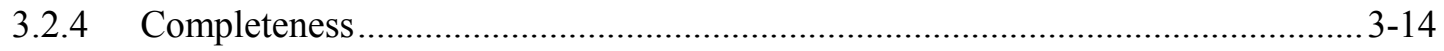




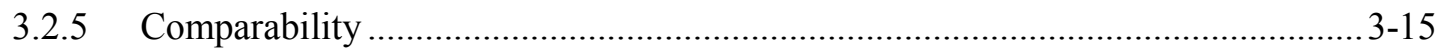

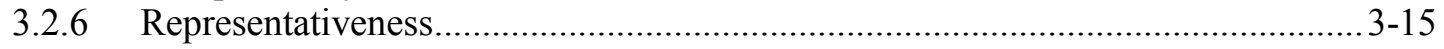

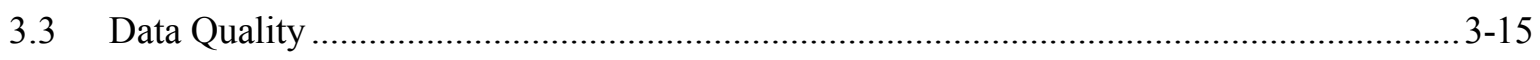

4. DOCUMENTATION AND SAMPLE CONTROL ............................................................. $4-1$

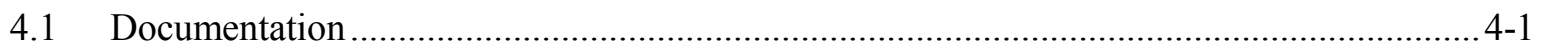

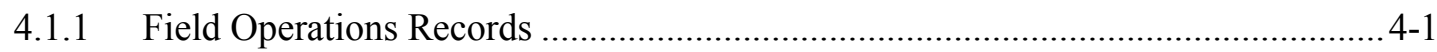

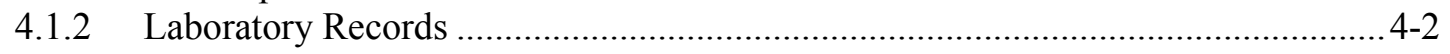

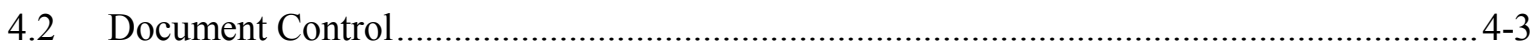

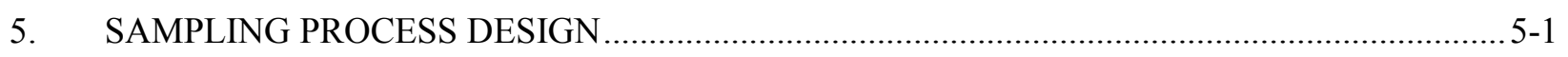

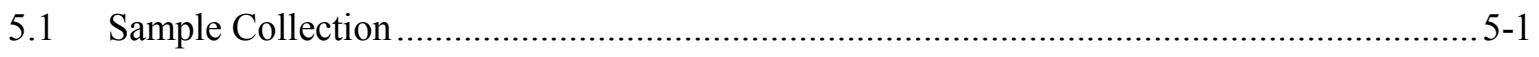

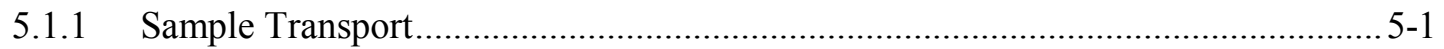

5.1.2 Sample Preservation ..................................................................... $5-2$

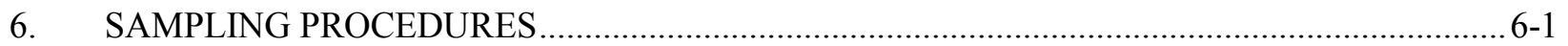

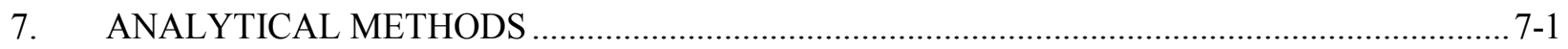

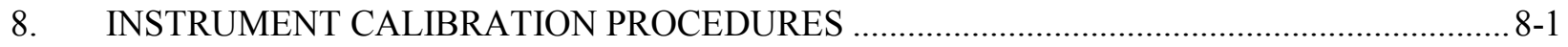

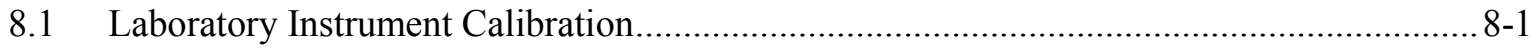

8.2 Field Equipment Calibration/Setup ........................................................................ 8 8 -

8.3 Preventative Maintenance Procedures and Frequency ..................................................... 8-1

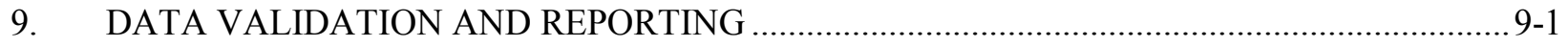

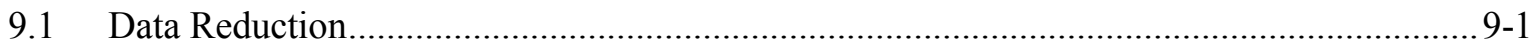

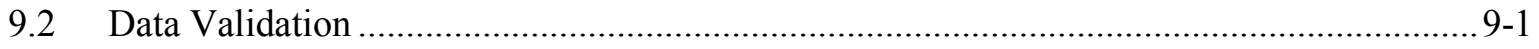

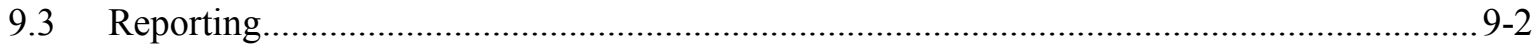

10. INTERNAL QUALITY CONTROL CHECKS AND FREQUENCY …................................. 10-1

10.1 Laboratory Quality Control........................................................................... 10-1

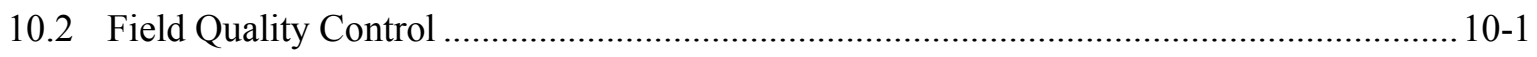

11. PERFORMANCE AND SYSTEMS AUDITS AND FREQUENCY ….................................. 11-1

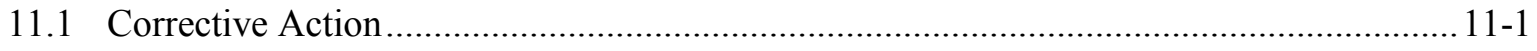

11.1.1 Laboratory Corrective Action ................................................................... 11-1 


\section{FIGURES}

3-1. Example of a decision performance goal diagram and corresponding decision error limits table

3-2. Schematic P-CLOS-TRA-731-4

\section{TABLES}

2-1. Key project positions and responsible personnel.......................................................................

3-1. Summary of analysis requirements for final rinsate samples collected from the TRA-731

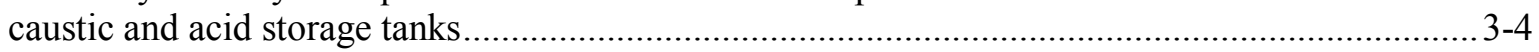

3-2. Number of samples required as a function of error tolerances, width of gray region, and anticipated data variability.

5-1. Summary of sample collection, hold time, and preservation requirements for samples collected..... collected.

7-1. Analytical method source documents and method summaries 


\section{ACRONYMS}

AA alternative action

AL action level

COC chain of custody

CV coefficient of variance

DOE U.S. Department of Energy

DOE-HQ U.S. Department of Energy Headquarters

DOE-ID U.S. Department of Energy Idaho Operations Office

DQA data quality assessment

DQO data quality objective

DS decision statement

EPA U.S. Environmental Protection Agency

ER environmental restoration

ESH\&Q environment, safety, health, and quality

FLAA flame atomic absorption

FSP Field Sampling Plan

FTL field team leader

HASP Health and Safety Plan

HDPE high-density polyethylene

HWMA Hazardous Waste Management Act

ICP inductively coupled plasma

IDAPA Idaho Administrative Procedure Act

IDEQ Idaho Department of Environmental Quality

IH industrial hygiene

INEEL Idaho National Engineering and Environmental Laboratory

INEL Idaho National Engineering Laboratory 


\begin{tabular}{|c|c|}
\hline JSS & job site supervisor \\
\hline $\mathrm{MCP}$ & management control procedure \\
\hline MDL & method detection limit \\
\hline OSHA & Occupational Safety and Health Administration \\
\hline PM & project manager \\
\hline PRD & program requirements document \\
\hline PSQ & principal study question \\
\hline QA & quality assurance \\
\hline QAO & quality assurance objective \\
\hline QAP & Quality Assurance Plan \\
\hline QAPjP & Quality Assurance Project Plan \\
\hline QC & quality control \\
\hline RCRA & Resource Conservation and Recovery Act \\
\hline RPD & relative percent difference \\
\hline SAP & Sampling and Analysis Plan \\
\hline $\mathrm{SC}$ & sample custodian \\
\hline SMO & Sample Management Office \\
\hline SOP & standard operating procedure \\
\hline SOW & statement of work \\
\hline TBD & to be determined \\
\hline TRA & Test Reactor Area \\
\hline UCL & upper confidence limit \\
\hline
\end{tabular}




\section{Quality Assurance Project Plan for the HWMA/RCRA Closure Certification of the TRA-731 Caustic and Acid Storage Tank System}

\section{INTRODUCTION}

This Quality Assurance Project Plan (QAPjP), used in conjunction with the Field Sampling Plan (FSP) (INEEL 2001a), comprises the Sampling and Analysis Plan (SAP) for the Hazardous Waste Management Act (HWMA)/Resource Conservation and Recovery Act (RCRA) Closure Certification of the TRA-731 caustic and acid storage tank system.

This QAPjP describes the sampling, analysis, and quality control procedures to be used for the post-decontamination characterization of the TRA-731 caustic and acid storage tank system at the Test Reactor Area (TRA), Idaho National Engineering and Environmental Laboratory (INEEL).

Characterization data will be used to certify closure under Idaho HWMA/RCRA requirements for closure of hazardous waste tank systems (IDAPA 58.01.05.009 [40 CFR 265.111 and 265.197]).

This plan presents the activities, organization, and quality assurance (QA)/quality control (QC) protocols to achieve specific data quality objectives (DQOs). This QAPjP will ensure compliance with the QA/QC requirements of the INEEL, the U.S. Environmental Protection Agency (EPA) Region 10, the U.S. Department of Energy Idaho Operations Office (DOE-ID), U.S. Department of Energy Headquarters (DOE-HQ), and the Idaho Department of Environmental Quality (IDEQ). This QAPjP is based on the requirements stated in EPA Guidance for Quality Assurance Project Plans (EPA 1998) and will serve as the governing document for all activities conducted in support of the post-decontamination characterization of the TRA-731 caustic and acid storage tank system.

\subsection{Site Background}

The TRA functions as a facility in support of nuclear research and development at the INEEL. To accomplish the TRA mission, pure demineralized water is needed in large volumes. Historically, caustic and acid solutions were used to regenerate the ion exchange columns formerly located in the Demineralizer Building (TRA-608), neutralize spent regenerant solutions in the elementary neutralization units (Brine Pit [TRA-731A] and the Regenerant Neutralization Tank [TRA-708C]), and supply acid to the secondary cooling systems at the Advanced Test Reactor and the Engineering Test Reactor. The TRA-731 caustic and acid storage tanks supplied the sodium hydroxide (caustic) and sulfuric acid to these processes from 1952 until 1992, at which time new bulk storage tanks located in Acid and Caustic Storage Building (TRA-677) were put into service.

Caustic and acid from the TRA-731 caustic and acid storage tanks were pumped from the tanks via pumps located in the Acid and Caustic Pump House (TRA-631) to the various processes described above or returned to the TRA-731 caustic and acid storage tanks. In Fall 1992, the TRA-731 caustic and acid storage tanks were taken out of service; however, the caustic and acid product was not removed from the tanks within 90 days after the tanks were removed from service and the caustic and acid product in the tanks became a waste subject to HWMA/RCRA regulations. The TRA-731 caustic and acid storage tank system includes the TRA-731B \& C caustic storage tanks, the TRA-731D \& E acid storage tanks, associated fill piping, and associated transfer piping. The storage tanks are located in the fenced area north of the Demineralizer Building (TRA-608), east of TRA-631. 
The tank system components to be closed and certified as part of the post-decontamination characterization consist of the four storage tanks. Associated piping and ancillary equipment have been or will be removed as part of past deactivation or under the approved HWMA/RCRA closure plan for the TRA-731 caustic and acid storage tank system. The East/West Trench and associated soils will be addressed under the Federal Facility Agreement and Consent Order.

The TRA-731 caustic and acid storage tank waste inventory was removed as part of deactivation activities in 1998 and the tank system will be closed under HWMA/RCRA. A tank system closure plan (DOE-ID 2001) has been submitted to the IDEQ for approval per the 1999 Consent Order resolving the 1997 Notice of Violation (Pisarski 1999) between the IDEQ and DOE-ID. A more detailed description of the TRA-731 caustic and acid storage tank system is included in the closure plan.

\subsection{Purpose of Sampling}

Sampling and analysis will be conducted to demonstrate that, following decontamination, the TRA-731 caustic and acid storage tanks do not pose a threat to human health. The purpose of the postdecontamination characterization is to determine if there are any hazardous constituents remaining in the TRA-731 caustic and acid storage tanks and, if so, that they are reduced to concentrations that meet the action levels specified in the HWMA/RCRA closure plan (DOE-ID 2001).

Samples of final rinsates collected from each of the caustic and acid storage tanks will be analyzed for a specified list of constituents to demonstrate that the HWMA/RCRA closure performance standard criteria specified in the HWMA/RCRA closure plan (DOE-ID 2001) have been satisfied. The data generated as a result of the sampling and analysis described in this QAPjP will be used to demonstrate compliance with the tank system closure performance standard specified in the 40 CFR 265.111 and 265.197.

\subsection{Analytical Laboratory}

The analytical laboratory chosen for conducting the analyses will have the appropriate level of qualified personnel, appropriate instrumentation, an approved quality assurance plan (QAP), approved analytical methods, and appropriate internal standard operating procedures (SOPs) to perform the required analyses. The selected laboratory will be approved for INEEL samples as certified by their inclusion on the INEEL-approved supplier's list. The QAPs and SOPs for the selected laboratory (or laboratories) will be available (at the laboratories) for review by project personnel and shall be provided to the INEEL upon request. 


\section{PROJECT ORGANIZATION AND RESPONSIBILITIES}

To ensure that project closure objectives, data gathering and reporting, data evaluation and interpretation, closure design, and health and safety plans meet INEEL requirements, the TRA-731 caustic and acid tank system post-decontamination characterization must have a clearly defined project organization. Table 2-1 provides a listing of project personnel and their responsibilities. The following sections outline the specific duties of project personnel throughout the closure certification effort. All project and support personnel will be expected to stop work at the site if an unsafe condition exists.

Table 2-1. Key project positions and responsible personnel.

\begin{tabular}{lll}
\hline \multicolumn{1}{c}{ Project Role } & \multicolumn{1}{c}{ Responsible Official } & Telephone Number \\
\hline TRA-731 closure project & George Swaney & $208-533-4380$ \\
TRA-731 closure project (alternate) & Douglas Archibald & $208-533-4599$ \\
TRA projects manager & Janis Sherick & $208-533-4290$ \\
INEEL Environmental Affairs closure & Susan Evans & $208-526-0186$ \\
TRA site area director & Chris Midgett & $208-533-4419$ \\
TRA outer area landlord & Michael Huyck & $208-533-4640$ \\
Job site supervisor & Dan Durocher & \\
Field team leader & To be determined (TBD) & \\
TRA environment, safety, health and & Brad Swanson & $208-533-4051$ \\
quality oversight & & \\
Sampling team members & TBD ${ }^{\text {a }}$ & \\
Data validation & TBD & \\
Data evaluation & TBD & \\
Data storage & TRA Projects & Not applicable \\
\hline
\end{tabular}

\subsection{Project Manager}

The TRA-731 closure project manager (PM) will ensure that all activities conducted during the project comply with INEEL management control procedures (MCPs), program requirements documents (PRDs), and all applicable Occupational Safety and Health Administration (OSHA), EPA, U.S. Department of Energy (DOE), U.S. Department of Transportation, and State of Idaho requirements. The PM coordinates all document preparation and all field, laboratory, data evaluation, risk assessment, dose assessment, and closure design activities. The PM is responsible for the overall work scope, schedule, and budget. 
The PM serves as the representative for the TRA facility operations at the site. The PM is responsible for field activities, crafts personnel, and other personnel assigned to work at the site. The PM will serve as the interface between operations and project personnel and will work closely with the sampling team at the site to ensure that the objectives of the project are accomplished in a safe and efficient manner. The PM will work with all other identified project personnel to accomplish day-to-day operations at the site, identify and obtain additional resources needed at the site, and interact with the TRA environment, safety, health, and quality (ESH\&Q) oversight personnel on matters regarding health and safety. The PM will conduct all daily prejob briefings.

\subsection{Sampling and Data Quality Personnel}

Sampling and data quality personnel will report directly to the PM. All sampling and data quality personnel will be responsible for the control and implementation of all QA/QC actions conducted during post-decontamination characterization and subsequent site closure activities. These actions include:

- Identification and reporting of all project data gathering efforts

- Oversight of all laboratory analysis and data reporting activities

- Oversight and reporting of all data validation and evaluation

- Identification and reporting of any deviations from project QA objectives

- Identification and implementation of any necessary corrective actions

- $\quad$ Performance monitoring of all field activities (e.g., sample collection, decontamination, and sample transport).

\subsection{Job Site Supervisor}

The job site supervisor (JSS) is responsible for interfacing with the PM to ensure coordination in accomplishing all required tasks.

\section{$2.4 \quad$ Field Team Leader}

The field team leader (FTL) will be delegated responsibility for the safe and successful completion of post-decontamination sampling of the final tank rinsates from the TRA-731 caustic and acid storage tanks. The FTL works with the JSS, the TRA ESH\&Q oversight personnel, and the field team to manage field sampling related operations and to execute the SAP. The FTL enforces site control, documents activities, and conducts the daily safety briefings at the start of each shift. Any team member may bring health and safety concerns to the attention of the FTL.

If the FTL leaves the site, an alternate will be appointed. The identity of the acting FTL will be conveyed to site personnel, recorded in the FTL logbook, and communicated to the facility representative, as appropriate. 


\subsection{TRA ESH\&Q Oversight}

The TRA ESH\&Q oversight personnel are the primary source for information regarding hazardous and toxic agents at the site. The TRA ESH\&Q oversight personnel assess the potential for worker exposures to hazardous agents according to the INEEL Safety and Health Manual, MCPs, PRDs, and accepted industrial hygiene $(\mathrm{IH})$ practices and protocol. By participating in site characterization, TRA ESH\&Q oversight personnel assess and recommend appropriate hazard controls for the protection of site personnel, and operate and maintain airborne sampling and other monitoring equipment, as appropriate. The TRA ESH\&Q oversight personnel also recommend and assess the use of personnel protective equipment in a Health and Safety Plan (HASP) or other health and safety documentation such as safe work permits.

In the event of an evacuation, the TRA ESH\&Q oversight personnel, in conjunction with other recovery team members, will assist the JSS and PM in determining whether conditions exist for safe site reentry. Personnel showing symptoms of health effects resulting from possible exposure to hazardous agents will be referred to an Occupational Medical Program physician by their supervisor or by TRA ESH\&Q oversight personnel. The TRA ESH\&Q oversight personnel may have other duties at the site, as specified in other sections of the PRDs and/or MCPs. During emergencies involving hazardous materials, airborne sampling and monitoring will be coordinated with members of the Emergency Response Organization.

\subsection{Sampling Team Members}

The sampling team will be fully trained and skilled in the standard sampling procedures for sampling tank contents and decontamination solutions collected during closure activities, a decontamination team, and TRA ESH\&Q oversight personnel. All sampling team personnel will have qualifications in compliance with the TRA-731 caustic and acid storage tank system training matrix. The team will be responsible for collecting samples in sufficient numbers to meet the requirements presented in the Field Sampling Plan for the HWMA/RCRA Closure Certification of the TRA-731 Caustic and Acid Storage Tank System (INEEL 2001a) and this QAPjP.

At the end of each sampling effort, the sampling team, under direct supervision of TRA ESH\&Q oversight personnel, will be responsible for removal and transport of any sampling equipment brought into the sampling area to a decontamination facility. Waste management will be performed according to the Field Sampling Plan (INEEL 2001a). The sampling team will then ensure that sampling equipment is ready for the next sampling effort according to the appropriate SOP.

Sampling team members will be experienced in all aspects of sampling media similar to the rinsates that will be collected from the TRA-731 caustic and acid storage tank system. They must be trained to procedures for collection of representative samples and trained to the many TRA and INEEL environmental safety and health procedures and policies. Senior personnel will also be familiar with the TRA-731 caustic and acid storage tank system. Each member of the sampling team will have up-to-date training relating to site hazards, including OSHA hazardous waste site worker training and other training deemed applicable by the PM, FTL, and Health and Safety Organization. 


\subsection{Laboratory Manager}

The laboratory manager will serve as the principal point of contact for coordinating field and laboratory activities. The responsibility of coordination may be delegated to a laboratory PM within the laboratory organization. The laboratory manager will have ultimate responsibility for the technical quality of all laboratory deliverables, cost control, and laboratory personnel management, and for ensuring that the samples are analyzed and data are reported on schedule.

\subsection{Laboratory Quality Assurance Officer}

The laboratory QA officer will evaluate all laboratory-generated data prior to release to:

- Determine if instrument calibrations were performed in accordance with the analytical statement of work (SOW), provided to the laboratory, prescribing analytical methods

- $\quad$ Determine if all method QC analyses comply with the requirements of the SOW and analytical methods

- Determine if the data reporting format complies with the requirements stipulated by the project in the SOW.

The laboratory QA officer will notify the TRA-731 closure PM of all noncompliance and will seek immediate corrective action through the TRA-731 closure PM.

\subsection{Laboratory Sample Custodian and Record Coordinator}

The laboratory sample custodian (SC) will be responsible for maintaining sample custody, assigning laboratory identification numbers, and storing samples. The SC will review all chain of custody (COC) forms, and all sample container identifications to ensure compliance with project procedures. In the event of field sampling errors, the SC will notify the FTL/field team members and seek to rectify the error immediately. All discrepancies will be documented in the laboratory logbook and copied to the laboratory QA officer and the PM to ensure that appropriate corrective actions have been developed. Discrepancies in sampling documentation are documented in the COC or on a sample-receiving checklist, which becomes part of the data package. The SC will report directly to the analytical operations supervisor who, in turn, reports to the laboratory manager. 


\section{QUALITY OBJECTIVES AND CRITERIA FOR MEASUREMENT DATA}

The overall objective of the TRA-731 caustic and acid storage tank system post-decontamination characterization is to obtain data that demonstrate that the closure performance standard, as identified in the HWMA/RCRA closure plan (DOE-ID 2001), has been satisfied. The DQOs are qualitative and quantitative statements, derived from the first six steps of the seven-step DQO process, that:

1. Clarify the study objective

2. Define the most appropriate types of data to collect

3. Determine the most appropriate conditions from which to collect the data

4. Specify tolerable limits on decision errors to be used as a basis for establishing the quantity and quality of data needed to support the decision(s) to be made using the data.

The criteria for measurement data are expressed as quality assurance objectives (QAOs). The measurement QAOs are specifications that data must meet to comply with the project needs specified by the DQOs. The specific QA parameters of interest are defined as quantitative QA parameters (precision, accuracy, method detection limit [MDL], and completeness) and qualitative QA parameters (representativeness and comparability).

\subsection{Data Quality Objectives}

The sampling objectives are discussed in the context of the DQOs process, as defined by EPA Guidance for the Data Quality Objectives Process (EPA 1994). This process was developed by the EPA to ensure that the type, quantity, and quality of data used in decision making are appropriate for the intended application. The DQO process includes seven steps, each of which has specific outputs. In this document, the DQO process has been applied to the sampling activities that will be conducted during the post-decontamination closure characterization of the TRA-731 caustic and acid storage tank system. Each of the following subsections corresponds to a step in the DQO process, and the outputs for each step are provided, as appropriate.

\subsubsection{Problem Statement}

The first step in the DQO process is to clearly state the problem to be addressed. The intent of this step is to clearly define the problem so the focus of the sampling and analysis will be unambiguous. The appropriate outputs for this step are a concise description of the problem, a list of the planning team members, identification of the decision-maker(s), a summary of available resources, and relevant deadlines for the study. The planning team members and decision-makers are identified in Section 2 of this QAPjP. The schedule is presented in the HWMA/RCRA Closure Plan for the TRA-731B and C Caustic and the TRA-731D and E Acid Storage Tank System (DOE-ID 2001).

The problem statement is as follows: Following decontamination, the TRA-731 caustic and acid storage tanks will be left in such a manner that the tanks are in compliance with the tank system closure performance standard specified in the HWMA/RCRA closure plan (DOE-ID 2001). Data are required to demonstrate that the HWMA/RCRA closure performance standard has been satisfied. 


\subsubsection{Decision Statement}

This step in the DQO process is used to identify the decisions and the potential actions that will be affected by the data collected. This is done by specifying principal study questions (PSQs), alternative actions (AAs) that could result from resolution of the PSQs, and combining the PSQs and AAs into decision statements (DSs).

The objective of sampling the final rinsate solutions from the TRA-731 caustic and acid storage tanks is to answer the following PSQ:

- $\quad$ PSQ: Have the tanks been decontaminated sufficiently to demonstrate compliance with the HWMA/RCRA closure performance standard?

The AAs to be taken depending on the resolution to the PSQ1 are as follows:

- AA1: If the concentrations of contaminants of concern detected in final rinsate solutions indicate that the closure performance standard criteria have been met, then the storage tanks have been decontaminated to the extent sufficient to allow closure of the TRA-731 caustic and acid storage tank system under HWMA/RCRA and closure certification can be completed.

- AA2: If the concentrations of contaminants of concern indicate that the performance standard criteria have not been met, then additional decontamination will be conducted.

Combining the PSQ1 and AAs results in the following DS:

- DS: Determine whether or not the decontamination activities have resulted in the tanks meeting the HWMA/RCRA closure performance standard and closure can be certified or if additional decontamination activities must be conducted.

\subsubsection{Decision Inputs}

The purpose of this step is to identify informational inputs that will be required to resolve the DS and to determine which inputs require measurements. The information needed to resolve the DS listed above is the identification and quantification of hazardous constituents present in final rinsates of the TRA-731 caustic and acid storage tanks.

When final rinsate characterization data show that the concentrations of contaminants of concern remaining in the storage tanks are below the action levels (ALs) specified in the tank system closure plan (DOE-ID 2001), decontamination operations will cease.

To resolve the DS, the concentrations of the hazardous constituents in the final tank rinsates, following completion of decontamination activities must be determined. There are existing data for the concentrations of hazardous constituents present in previous tank rinses. The existing data are relevant to this study because they provide the minimum list of constituents for which analyses should be performed. The existing data cannot be used to support closure certification because only one sample was analyzed from each tank and levels of the contaminants of concern in the tank rinsates did not meet the action levels specified in the HWMA/RCRA closure plan (DOE-ID 2001). 
During this step of the DQO process, the basis for an AL is established. The AL is the threshold value that provides the criterion for choosing among alternative actions. Action levels for rinsates have been developed and are set out in the HWMA/RCRA closure plan, Table 5-2 (DOE-ID 2001). For each contaminant of concern, an AL has been specified. If decontamination activities result in true mean concentrations (as estimated by the $90 \%$ upper confidence limit (UCL) of the sample mean) for all constituents that are below the AL, further decontamination of the tanks will not be required. The constituent-specific ALs were developed by defining the acceptable excess cancer risk and hazard quotient thresholds and calculating corresponding action levels based upon these risk and hazard thresholds for a future residential receptor via the soil ingestion and inhalation pathways (as discussed in Appendix B of the HWMA/RCRA closure plan [DOE-ID 2001]).

\subsubsection{Study Boundaries}

This step in the DQO process defines the spatial and temporal boundaries of the study covered by the DS. The spatial boundaries simply define the physical extent of the study area and may be subdivided into specific areas of interest. The temporal boundaries define the duration of the study, or specific parts of the study. The appropriate outputs of this step are a detailed description of the spatial and temporal boundaries of the problem and a discussion of any practical constraints that may interfere with the study.

The physical boundaries of the TRA-731 caustic and acid storage tank system, for purposes of post-decontamination sampling, are the four individual storage tanks themselves. The media that will be sampled to resolve the DS are the final rinsate solutions removed from the storage tanks following decontamination activities.

Defining the temporal boundaries of the study involves specifying the time frame in which the decision applies and determining when to collect data. The time period within which to collect the data is determined by decontamination operations and the approved HWMA/RCRA closure schedule. Once field or screening level laboratory measurements indicate that decontamination has reached a stable level, decontamination will cease and sample collection of the final rinsate solutions will commence.

The conceptual design of the rinsate sample collection activities does not provide any practical constraints on sample collection. Any limitations to data quality/usability introduced by sample collection constraints will be discussed in closure activity summary reports.

\subsubsection{Decision Rule}

The objective of this step is to define the parameters of interest that characterize the population, specify the AL, and integrate previous DQO outputs into a single statement defining conditions that direct decision-makers to choose among AAs. The decision rule typically takes the form of an "If...then" statement describing the action to take if one or more conditions are met.

The decision rule is specified in relation to a statistical parameter that characterizes the population of interest. It is assumed that the final rinsate solutions from each of the TRA-731 caustic and acid storage tanks will be $>99 \%$ liquid. If the sampled rinsate solution for a given tank contains significant solids (e.g., $>1 \%$ ), it is assumed that decontamination activities will continue until the final rinsate solution for that tank contains essentially no solids. Because of this, it is assumed contaminants in the final rinsate solution collected for any particular tank will be relatively equally distributed. Therefore, the parameter of interest for these liquids will be the true mean concentration (as estimated by the $90 \%$ UCL of the sample mean) of the contaminants of concern. 
of decision errors can be controlled by adopting a scientific approach. In this approach, the data are used to select between one condition of the environment (in this case, the environment is the post-decontamination tank rinsate) and the alternative condition. One of these conditions is assumed to be the baseline condition and is referred to as the null hypothesis $\left(\mathrm{H}_{0}\right)$. The alternative condition is the alternative hypothesis $\left(\mathrm{H}_{\mathrm{a}}\right)$. The null hypothesis is presumed to be true in the absence of strong evidence to the contrary. This feature provides a way for the decision-makers to guard against making the decision error with the most undesirable consequences.

A decision error occurs when the decision-maker rejects the null hypothesis when it is true, or fails to reject the null hypothesis when it is false. These two types of decision errors are classified as false positive and false negative decision errors, respectively.

A false positive decision error occurs when the decision-maker rejects the null hypothesis $\left(\mathrm{H}_{0}\right)$ when it is true. For example, a decision-maker presumes a certain waste is hazardous (i.e., the null hypothesis is "the waste is hazardous"). If the data cause the decision-maker to conclude that the waste is not hazardous when it truly is hazardous, then the decision-maker would make a false positive decision error. Statisticians refer to this error as a Type I error. The measure of the size of this error is called alpha $(\alpha)$, the level of significance, or the size of the critical region.

A false negative error occurs when the decision-maker fails to reject the null hypothesis when it is false. In the waste example given above, the false negative decision would be to use the data to conclude that the waste is hazardous when, in fact, it is not. Statisticians refer to false negative decision error as Type II error. The measure of the size of this error is called beta $(\beta)$, and is also known as the compliment of the power of a hypothesis test.

The possibility of decision error cannot be eliminated but it can be minimized, which is accomplished by controlling the total study error. Methods for controlling total study error include collecting a large number of samples (to control sampling design error), analyzing individual samples several times, or using more precise analytical methods (to control measurement error). The chosen method for reducing decision errors depends on where the greatest component of total study error exists in the data set and the ease in reducing the error contributed by those data components. The amount of effort expended on controlling decision error is directly proportional to the consequences of making an error.

The two types of decision error for the characterization of final rinsate data from the TRA-731 caustic and acid storage tanks are either determining that the final rinsate solution indicates that a tank does not contain contaminants exceeding the action levels when, in fact, it does, or determining that the final rinsate data indicates that a tank contains contaminants exceeding the action levels when, in fact, it does not. The consequences of each decision error must be considered. Concluding that the final rinsates from a tank are below action levels when they are not would result in the assumption that the tank could be certified as closed under HWMA/RCRA. The consequences of this erroneous conclusion would be fewer controls in place to ensure protection of the public and the environment following closure when these controls should be in place. 
Concluding that the final rinsate contaminant of concern concentrations from a tank are above action levels when they are not would result in the commencement of additional decontamination activities. The consequences of this conclusion would be the further expense of project resources to complete unnecessary decontamination activities, exposure of workers to additional risk associated with continued decontamination activities, public perception issues as the project schedule may be unnecessarily lengthened, and the potential for the generation of unnecessary waste in the form of additional decontamination solutions.

The decision error that has the more severe consequences as the true concentrations of the parameter of interest (in this case the true mean concentration) approach the action level must be specified, as it is the basis for establishing the null hypothesis. The decision error that has the more severe consequences as the true state approaches the action level is used because as the parameter approaches the $\mathrm{AL}$, the data are much more likely to lead to an incorrect decision than when the parameter is far above or below the AL. In problems that concern regulatory compliance, human health, or environmental risk, the decision error that has the most adverse consequences will be favored as the null hypothesis. In statistical hypothesis testing, the data must conclusively demonstrate that the null hypothesis is false. Therefore, setting the null hypothesis to the condition that exists when the more adverse decision error occurs guards against making the more severe decision error by placing the burden of proof on demonstrating that the most adverse consequences will not be likely to occur.

For tank decontamination, the more adverse decision error occurs when it is determined that a tank may be certified as closed when it may not. Because of this, the null hypothesis will be set as "the final rinsate solutions from a tank following decontamination indicates that there are contaminants of concern in excess of the action levels and closure cannot be certified." The alternative hypothesis then becomes, "the final rinsate solutions from a tank following decontamination indicate that rinsates do not contain contaminants of concern in excess of the action levels and closure can be certified."

Based on these null and alternative hypotheses, the false positive and false negative decision errors for tank decontamination can now be identified. The false positive decision error corresponds to the more severe decision error. The false positive error would be to conclude that the final rinsate contaminant of concern concentrations from a tank following decontamination indicate that contaminants of concern do not exceed action levels when, in fact, they do. The false negative decision error would be to conclude that the final rinsate contaminant of concern concentrations from a tank following decontamination indicate that contaminants of concern exceed action levels when, in fact, they do not.

A range of possible parameter values must be specified where the consequences of decision errors are relatively minor. This range of parameter values is referred to as the "gray region." The gray region is bounded on one side by the AL and on the other side by the parameter value where making a false negative decision error begins to be significant (U). It is necessary to specify the gray region because the variability in the population and unavoidable imprecision in the measurement system combine to produce variability in the data such that a decision may be "too close to call" when the true parameter value is very close to the AL. In statistics, this interval is called the "minimum detectable difference" and is expressed with the Greek letter delta $(\Delta)$. The width of this gray region is a critical part of the calculation for determining the number of samples needed to satisfy the DQOs and represents one important aspect of the decision-maker's concern for controlling decision errors. A narrow gray region implies a desire to detect conclusively the condition when the true parameter value is close to the AL. From a practical standpoint, the gray region is an area where it will not be feasible to control false negative decision error rate to low levels because of high costs. 
While the costs of making a false negative decision error for this closure activity are high, it is also true that a wider gray region can be selected. This is because previous decontamination activities have already been conducted, reducing the true mean concentration to low levels, and laboratory-screening analyses will be conducted during decontamination activities. Therefore, the screening data coupled with previous rinsate data will indicate that the true mean concentration has been reduced to very low levels prior to collection of the samples that will be used for final decision making. The project can use this incremental approach of decontamination and screening analyses to justify a gray region bounded on one side by the AL and the other by a concentration that is $50 \%$ of the constituent-specific AL. This says that because the project believes that decontamination activities will result in contaminant of concern concentrations being reduced well below $50 \%$ of the AL, controlling false negative decision error when the true mean is between $50-100 \%$ of the AL is of no concern.

The final activity required in specifying the tolerable limits on decision error is to assign limits to points above and below the gray region that reflect the probability of occurrence of decision errors. These probability values are the decision-maker's tolerable limits for making an incorrect decision. This is done by selecting a possible true value for the parameter of interest, then choosing a probability limit based on an evaluation of the seriousness of the potential consequences of making a decision error if the true parameter value is located at that point. The EPA guidance recommends evaluating sampling designs starting with a $1 \%(0.01)$ decision error rate. This percentage should neither be considered a prescriptive value for setting decision error rates nor a policy of EPA, merely a starting point from which to develop decision errors appropriate to the study. These concepts are presented in Figure 3-1.

The project team must use the three variables (width of gray region, acceptable false positive decision error rate when the true mean concentration is equal to the AL, and acceptable false negative decision error rate when the true mean concentration is equal to $U$ ) and adjust them to acceptable tolerances. Once this is done, an estimate of the number of samples required to satisfy the DQOs may be determined. Alternatives for sample collection design are discussed in the next section. An acceptable false positive decision error rate of 0.10 when the true mean concentration is equal to the AL and an acceptable false negative decision error rate of 0.20 when the true mean concentration is equal to $U$ have been selected for the post-decontamination sampling of the TRA-731 caustic and acid storage tanks. 


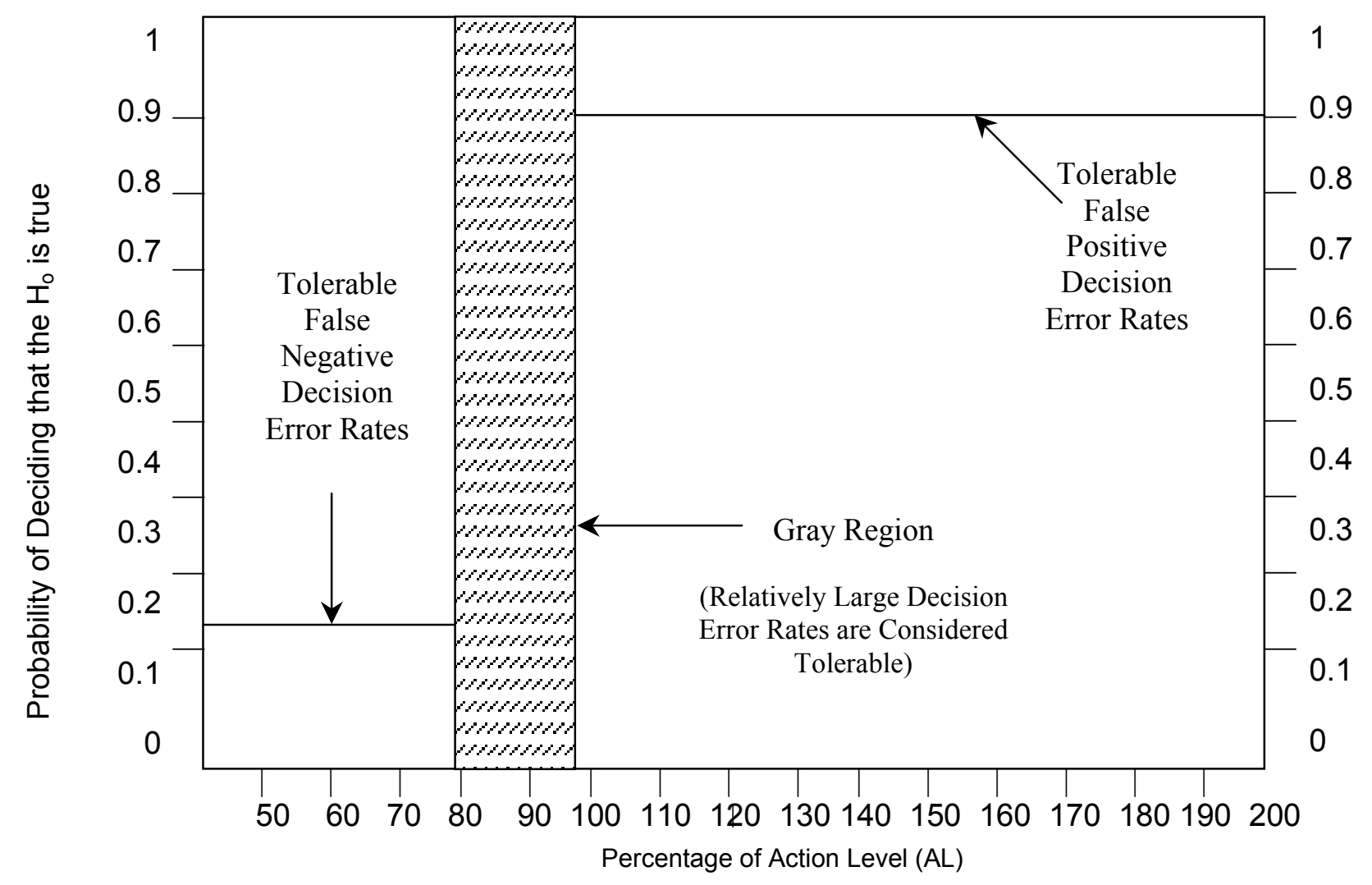

True Value of the Parameter (Mean Concentration, ppm)

Baseline condition: Parameter exceeds action levels.

\begin{tabular}{|cccc|}
\hline True Concentration & Correct Decision & Type of Error & $\begin{array}{c}\text { Tolerable Probability of } \\
\text { Incorrect Decision }\end{array}$ \\
\hline \hline$<80 \% \mathrm{AL}$ & Not exceed & $\mathrm{F}(-)$ & $20 \%$ \\
80 to $100 \mathrm{AL}$ & Not exceed & $\mathrm{F}(-)$ & Gray region \\
$>100 \% \mathrm{AL}$ & Does exceed & $\mathrm{F}(+)$ & $10 \%$ \\
\hline
\end{tabular}

Figure 3-1. Example of a decision performance goal diagram and corresponding decision error limits table.

\subsubsection{Design Optimization}

The purpose of design optimization in the DQO process is to identify the best sampling and analysis design that satisfies all of the previous steps in the process. The activities involved in design optimization include:

- $\quad$ Reviewing the outputs of the first six steps and existing environmental data

- $\quad$ Developing general data collection design alternatives 
- Formulating a mathematical expression needed to solve the design problem for each data collection design alternative

- Selecting the optimal number of samples to satisfy the DQOs for each data collection design alternative

- $\quad$ Selecting the most resource-effective data collection design that satisfies all the DQOs.

After these activities have been completed, the operational details and theoretical assumption of the selected design are documented in the SAP.

The outputs of the first six steps have been discussed previously. There are existing rinsate data for the TRA-731 caustic and acid storage tanks. However, these data cannot be used to support closure certification because only one sample was analyzed from each tank. Also, as no data exist for the characterization of tank contents following final decontamination activities, only assumptions of parameter variability and possible concentration ranges may be made.

The planning assumptions for the TRA-731 caustic and acid storage tank system closure project include some related to sample collection. Specifically, the assumption has been made that the samples of final rinsate solutions collected (decontamination solutions from the tanks) will be representative of the tank contents. That is, if only a liquid phase is obtained using these techniques, the solid phase (if one exists) is assumed to be inconsequential and may be ignored. If significant solid phase is obtained, it will be assumed that decontamination is incomplete and additional decontamination will occur prior to sampling the final rinsate for the TRA-731 caustic and acid storage tanks in question.

Sample locations were selected randomly by dividing each tank into 18 one-foot increments along the centerline of the tank, numbering each section from West to East. Sampling locations (see Schematic P-CLOS-TRA-731-4) were selected using a random number generator.

When using a simple or composite random sampling approach, there are commonly accepted mathematical expressions (e.g., the Student's $t$ distribution [Kachigan 1982]) to solve design problems for these data collection design alternatives.

The formula for determining the sample size (number of samples to be collected) is chosen based on the hypothesis test and data collection design. In this case, the hypothesis test will be a one sample Student's $t$ distribution of the mean versus action level. Using this hypothesis test, the formula shown in Equation 3-1 is used for computing the number of samples required for a simple random sampling approach:

$n=\frac{\sigma^{2}\left(z_{1-\beta}+z_{1-\alpha}\right)^{2}}{\Delta^{2}}+(0.5) z_{1-\alpha}^{2}$

where:
$\sigma^{2} \quad$ estimated variance in measurements
$n=\quad$ number of samples required
$z_{p} \quad$ the $\mathrm{p}^{\text {th }}$ percentile of the standard normal distribution (from statistical tables) 
$\Delta=\mathrm{AL}-\mathrm{U}($ the minimum detectable difference)

$\mathrm{U}=$ parameter value where making a false negative decision error begins to be significant

$\mathrm{AL}=$ action level

Table 3-2 illustrates numbers of samples required to satisfy DQOs when the variables of this equation are modified, as indicated in the table.

Using the data in the table, a minimum number of samples for each tank can be derived. It is assumed that the variability of the liquid matrix will be low (it will be relatively homogeneous throughout the volume remaining in the tank and a low variance $\left(\sigma^{2}\right)$ can be chosen. A low coefficient of variance is appropriate for rinsate sampling because it is assumed that the final rinse solutions from the TRA-731 caustic and acid storage tanks will be $>99 \%$ liquid. If the final rinsate for a given tank contains significant solids (e.g., $>1 \%$ ), it is assumed that decontamination activities will continue until the final rinsate solution for that tank contains essentially no solids. Because of this, it is assumed contaminants in the final rinsate collected for any one tank will be relatively equally distributed. It is also assumed that based on the decontamination process, the conensates collected in the bottom of the tanks will be mixed.

Using a concentration that is $15 \%$ of the AL as $\sigma$, and assuming an acceptable chance of false positive decision error to be $10 \%$ when the true concentration is equal to the $\mathrm{AL}$, an acceptable chance of false negative decision error to be $20 \%$ when the true concentration is equal to $\mathrm{U}$, and the width of the gray region is $50 \%$ of the $\mathrm{AL}$, the appropriate number of liquid samples to collect from each tank would be 1.23, or two samples. Equation 3-2 shows the solution for $n$ (Equation 3-1) using the appropriate variables:

$n=\frac{15^{2}(0.842+1.282)^{2}}{50^{2}}+(0.5)(1.282)^{2}=1.227786$

The selection of the statistical hypothesis test used for the data will be discussed in the data quality assessment (DQA) report for the closure activity. Because the decontamination solutions are expected to be essentially contaminant free, it is likely that the data will exhibit a normal distribution and the statistical hypothesis will be tested using the one-sample $t$-test. The data obtained from each tank will be evaluated separately to identify if any of the tanks require additional decontamination (i.e., the null hypothesis can not be rejected).

\subsection{Measurement Performance Criteria}

The DQOs provide the basis for setting criteria for the performance of the measurements to be made in the field and analytical laboratory. These criteria are specified as data QAOs. Quantitative QAOs are developed by data users to specify the quality of data from field and laboratory data collection activities. The QAOs are established to ensure that all project DQOs are met and that resulting data support the decision-making activities that will ultimately occur at the site.

The overall goal of the TRA-731 caustic and acid storage tank system QAOs is to ensure that sufficient data are gathered to support a closure certification. The following sections outline the specific parameters that will be used to evaluate the quality of data obtained during the post-decontamination characterization of the TRA-731 caustic and acid storage tank rinsates. 


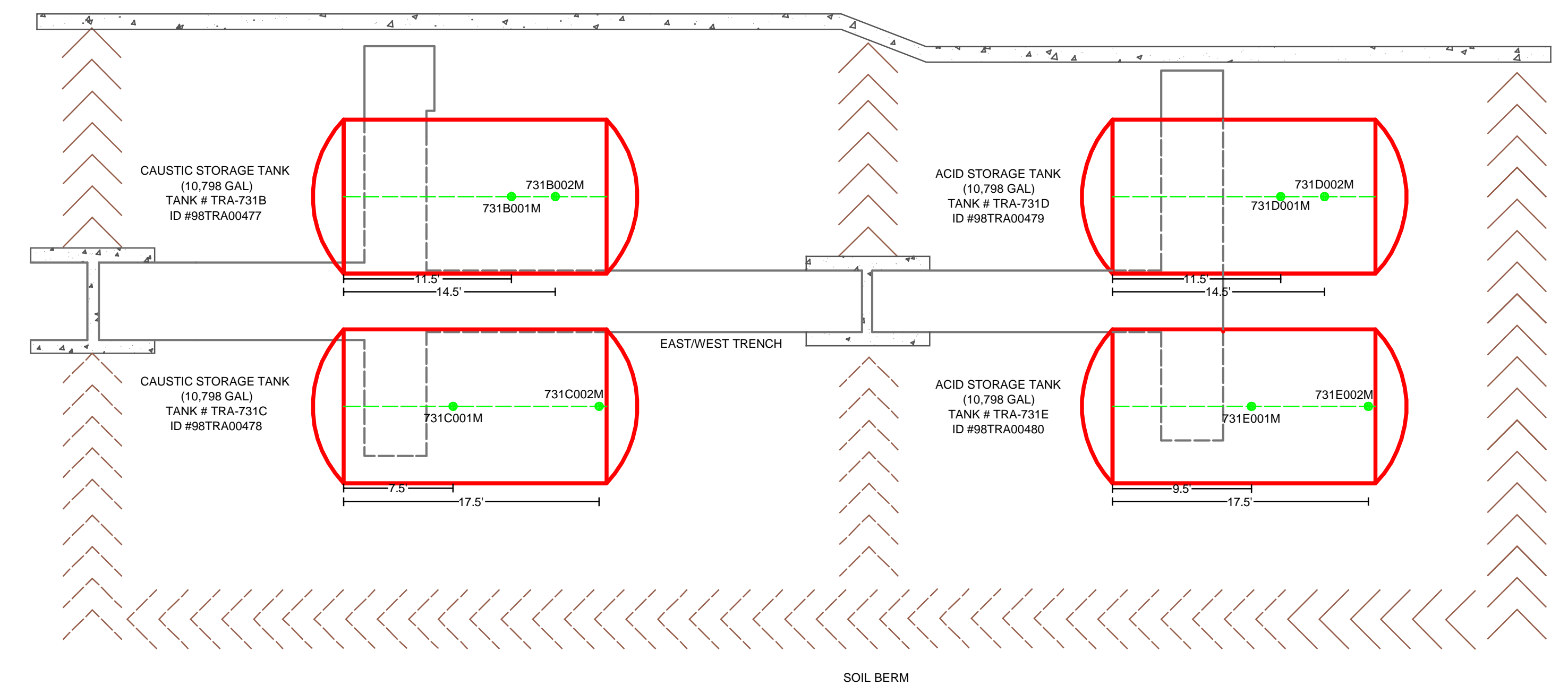

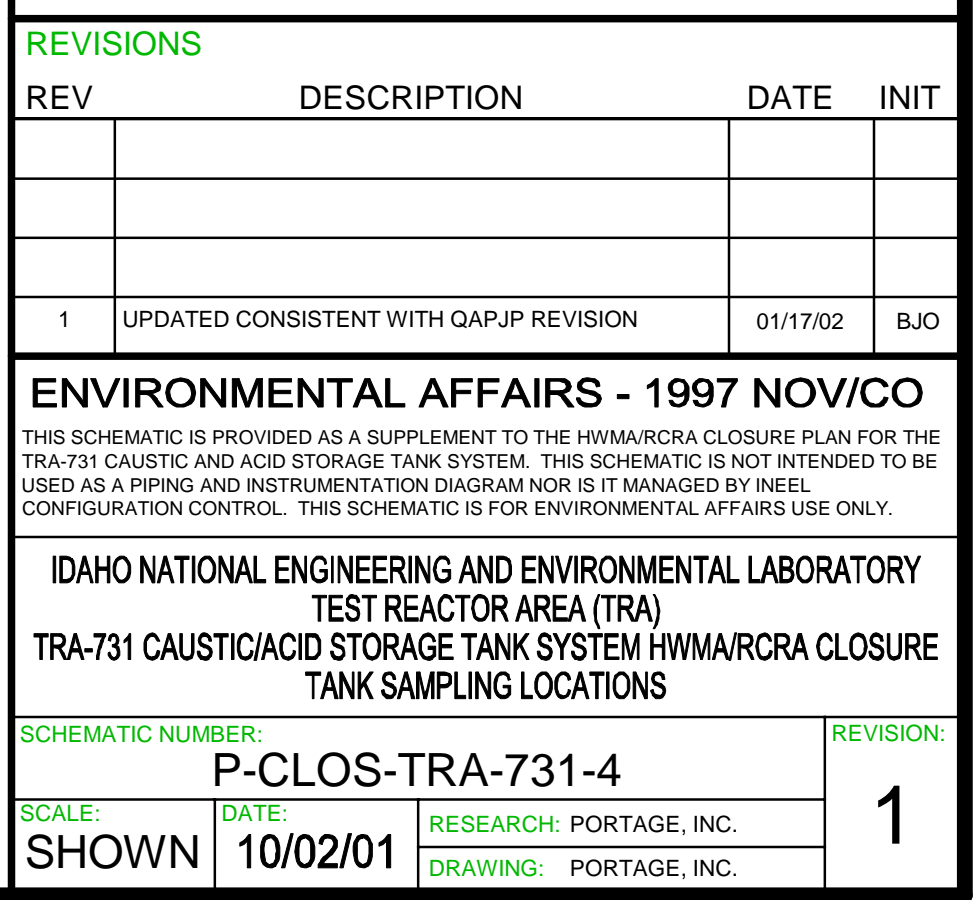


Table 3-2. Number of samples required as a function of error tolerances, width of gray region, and anticipated data variability. ${ }^{\mathrm{a}}$

\begin{tabular}{ccccccc}
\hline \multicolumn{3}{c}{ Confidence Level } & \multicolumn{3}{c}{ Power } \\
\hline 1-alpha & alpha & $\mathrm{Z}_{1-\alpha}$ & & 1-beta & beta & $\mathrm{Z}_{1-\beta}$ \\
\cline { 3 - 5 } 0.8 & 0.2 & 0.842 & & 0.8 & 0.2 & 0.842 \\
0.85 & 0.15 & 1.039 & & 0.85 & 0.15 & 1.039 \\
0.9 & 0.1 & 1.282 & & 0.9 & 0.1 & 1.282 \\
0.95 & 0.05 & 1.645 & & 0.95 & 0.05 & 1.645 \\
0.99 & 0.01 & 2.326 & & 0.99 & 0.01 & 2.326
\end{tabular}

\section{$\mathbf{N}=$ sample number}

14.271112

9.9203415

10.505078

18.399986

27.118146

44.649413

35.622329

4.865858

2.892131

4.865858

18.265669

3.359411

14.208214 for $\mathrm{CV}=30, \mathrm{MDRD}=20$, Confidence $=80$, Power $=95 \quad 1$ sided, 1 sample for $\mathrm{CV}=20, \mathrm{MDRD}=20$, Confidence $=95$, Power $=90 \quad 1$ sided, 1 sample for $\mathrm{CV}=30, \mathrm{MDRD}=20$, Confidence $=80$, Power $=90 \quad 1$ sided, 1 sample for $\mathrm{CV}=40, \mathrm{MDRD}=20$, Confidence $=80$, Power $=90 \quad 1$ sided, 1 sample for $\mathrm{CV}=40, \mathrm{MDRD}=20$, Confidence $=90$, Power $=90 \quad 1$ sided, 1 sample for $\mathrm{CV}=40, \mathrm{MDRD}=20$, Confidence $=95$, Power $=95 \quad 1$ sided, 1 sample for $\mathrm{CV}=40, \mathrm{MDRD}=20$, Confidence $=95$, Power $=90 \quad 1$ sided, 1 sample for $\mathrm{CV}=20, \mathrm{MDRD}=20$, Confidence $=80$, Power $=90 \quad 1$ sided, 1 sample for $\mathrm{CV}=15, \mathrm{MDRD}=20$, Confidence $=80$, Power $=90 \quad 1$ sided, 1 sample for $\mathrm{CV}=15, \mathrm{MDRD}=15$, Confidence $=80$, Power $=90 \quad 1$ sided, 1 sample for $\mathrm{CV}=25, \mathrm{MDRD}=20$, Confidence $=95$, Power $=95 \quad 1$ sided, 1 sample for $\mathrm{CV}=15, \mathrm{MDRD}=20$, Confidence $=90$, Power $=80 \quad 1$ sided, 1 sample for $\mathrm{CV}=25, \mathrm{MDRD}=20$, Confidence $=90$, Power=95 1 sided, 1 sample

a. Derived from Guidance for Data Usability in Risk Assessment (Part A) (EPA 1992).

Recommend: $\quad$ Minimum confidence $=90$ (Type I, false positive)

Minimum compliment of the power $=80$ (Type II, false negative)

$\mathrm{CV}=$ Coefficient of variance (expressed as a percentage of the AL)

MDRD = Minimum detectable relative difference. EPA defines the MDRD as the lowest value (expressed as a percentage of the $\mathrm{AL}$ ) where a statistical difference can be determined. 


\subsubsection{Precision}

Precision is a measure of agreement or reproducibility among individual measurements for the same property under the same conditions. Precision is expressed as relative percent difference (RPD), which is defined, and shown in Equation 3-3, as the absolute value of the difference divided by the mean, expressed as a percentage.

$R P D=\frac{(M S-M S D)}{(M S+M S D) / 2} \times 100$

where:
$M S=$ Measured concentration of parameter in matrix spike sample
$M S D=$ Measured concentration of parameter in matrix spike duplicate sample.

The analytical laboratory will report the precision of their measurements in the sample matrix based on the results obtained from the matrix spike and matrix spike duplicate analyses. For some inorganic measurements, precision will be calculated using duplicate measurements of the same sample. Replicate measurements are used for metals determinations after sample preparation, during instrumental analysis, and for mercury determinations post-digestion.

Acceptable laboratory precision will be determined by method-specific criteria outlined in SW-846, Test Methods for Evaluating Solid Waste, Physical/Chemical Methods (EPA 1986) and the laboratory statement of work. During DQA activities, precision of the environmental measurements will be assessed to determine if there are any impacts on hypothesis testing due to the precision of the data.

\subsubsection{Accuracy}

Accuracy is the relative agreement or disagreement between a measured value and an accepted reference value. Accuracy reflects the measurement error associated with a measurement and is determined by comparing actual measurements in the sample matrix to the results of the matrix spike data. Accuracy is assessed by means of laboratory reference samples and expressed as a percent recovery $(\% \mathrm{R})$, defined as the measured value divided by the true value expressed as a percent, as shown in Equation 3-4.

$\% R=\frac{C_{s s}-C_{u s}}{C_{a s}} \times 100$

where:

$$
\begin{aligned}
& \% R=\text { percent recovery } \\
& C_{s s}=\text { measured analyte concentration in spiked sample } \\
& C_{u s}=\text { measured analyte concentration in nonspiked sample } \\
& C_{a s}=\text { calculated analyte concentration added to sample. }
\end{aligned}
$$


The analytical laboratory will report the accuracy of their measurements in the sample matrix based on the results of the matrix spike data. Acceptable laboratory accuracy will be determined by assessing the results against method-specific criteria outlined in SW-846 (EPA 1986) for total metals. During DQA activities, accuracy of the environmental measurements (in the form of bias that may be indicated by the measure discussed above) will be assessed to determine if there are any impacts on hypothesis testing due to the accuracy of the data.

\subsubsection{Detection Limits}

The laboratory will use guidance found in SW-846 (EPA 1986) to aid in setting baselines for MDLs for inorganic analytical methods. The MDLs are defined as the minimum concentration of a substance that can be reliably measured and reported by a particular analytical method. Matrix effects, sample size, or other analytical interference may increase MDLs. The effects of these conditions on the laboratory's MDLs, if determinable, will be documented.

Chemical methods for all total metals and anions typically use the standard deviation of replicate measurements of standards multiplied by a factor specified by the method or laboratory SOW to determine minimum MDLs. Estimated detection limits are provided in each of the appropriate analytical methods for chemical determinations and serve as a guide for purposes of this QAPJP. The laboratory will use standard chemical analysis practices to ensure the MDLs approach those prescribed in the analytical laboratory SOW. Any significant deviations will be identified in the reported data.

The laboratory analysts will follow the SW-846 (EPA 1986) methods as closely as possible to ensure the data are compliant with the requirements of the project. Deviations from the protocols presented in SW-846 (EPA 1986) may occur during the analysis of the post-decontamination rinsates as a result of sample size constraints. A smaller sample size may introduce a dilution effect, thereby elevating the detection level for a given sample or analysis. In the event that sample volume (or mass) prohibits the use of SW-846 (EPA 1986) protocols, the laboratory will make a good faith effort to assign methods that will provide acceptable/usable data and document all method deviations in the case narrative provided with the data package.

\subsubsection{Completeness}

Completeness is the measure of the amount of valid analytical data obtained compared to the total number of data points planned. Valid analytical data are those generated when analytical systems and the resulting analytical data meet all DQOs outlined for the project (i.e., all calibration verification, interference, and other checks not affected by the sample matrix meet acceptance criteria). It is important to understand that data that are flagged during the data validation process are not necessarily invalid data. Part of the DQA process is the review of flagged data to determine whether the validation flags impact the intended use of the data. Therefore, the definition of "valid data" in the context of calculating completeness is: "data that are acceptable for their intended purpose." Completeness of the reported data (expressed as a percentage) is calculated, as shown in Equation 3-5.

$\mathrm{C}(\%)=M_{v} / M t \times 100$

where:
$M_{v} \quad=\quad$ number of measurements determined to be valid per analyte
$M t=$ total number of measurements performed per analyte 
A completeness of $90 \%$ is a common goal. All data obtained from this project should meet the quality requirements and reporting protocols unless irregularities in the matrix (a.k.a. matrix effects) impede contaminant recovery or a broken, spilled container results in a loss of sample materials. The completeness goal for the project is to obtain enough valid data to satisfy the DQO specifications for the number of measurements required to statistically test the null hypothesis (see Section 3.1.7).

\subsubsection{Comparability}

Comparability is the degree to which one data set can be compared to another obtained from the same population using similar techniques for data gathering. Comparability will be achieved through the use of consistent sampling procedures, experienced sampling personnel, the same analytical method for like parameters, standard field and laboratory documentation, and traceable laboratory standards.

\subsubsection{Representativeness}

Representativeness is a measure of the degree to which data accurately and precisely represent a characteristic of a population parameter at a sampling point, a process condition, or an environmental condition. Representativeness is a qualitative term that should be evaluated to determine whether in situ and other measurements are made and physical samples are collected in such a manner that the resulting data appropriately reflect the media and phenomenon measured or studied.

The sampling design discussed in Section 3.1.7 of this plan is the basis for obtaining data that will be representative of the post-decontamination tank rinsate solutions. A final determination of representativeness for the initial data set will be made by the PM and other project personnel following the return of the analysis data.

\subsection{Data Quality}

The data generated from the post-decontamination characterization effort for the TRA-731 caustic and acid storage tanks will be used to evaluate parameters that are pertinent to the closure process. Each parameter to be evaluated requires data of specific quality. To demonstrate compliance with the closure requirements, the chemical measurement data obtained must be of high quality. Laboratory analytical procedures and laboratory data reporting will follow the QA/QC protocols described in SW-846 (EPA 1986) and ER-SOW-156 (INEL 1995).

The laboratory staff and their experience will be relied upon, in conjunction with the PM, to make the best decisions for analyses where deviations may arise. The laboratory will flag nonconforming data, as appropriate and required in the analytical laboratory SOW. 


\section{DOCUMENTATION AND SAMPLE CONTROL}

Documentation involves recording all events relating to field and laboratory activities. Typical field documentation will include field logbooks, sample labels, and COC forms. Sample handling procedures include COC, sample- and investigation-derived waste packaging, and sample transport.

\subsection{Documentation}

To ensure that all sampling, analysis, and data reporting activities are conducted in accordance with project DQOs and all appropriate safety procedures, adequate documentation of each event must be completed. Therefore, all field activities related to sample collection, site safety, and sample custody must be recorded by the FTL and/or the field team members in the field logbook. In addition, all laboratory activities relating to sample custody, sample preparation, sample analysis, and data reporting must also be completely recorded to ensure that laboratory data can be confidently assigned to field sample points.

The laboratory will perform all functions relating to TRA-731 caustic and acid storage tank system samples in accordance with an appropriate laboratory QAP. In addition, TRA-731 closure project management and other key project staff may contact the laboratory personnel and obtain a copy of the laboratory QAP and/or visit the facility to ensure that laboratory procedures meet the project-specific goals.

\subsubsection{Field Operations Records}

The following sections provide a summary of requirements for adequate field documentation. All field documentation, document control, and daily updating of field logbooks and field materials will be the responsibility of the FTL or designee.

4.1.1.1 Sample Container Labels. Preprinted labels will be affixed to the sample containers before use and will contain the name of the project, sample identification number, location, and requested analysis. Following collection, the date and time of collection and the sample team member's initials will be recorded with a waterproof black marker on the sample label. The samples will be placed in coolers with blue ice, if required, while awaiting preparation and shipment to the appropriate laboratory.

4.1.1.2 Sample Numbering Scheme. Each sample will be assigned a unique identification number. A systematic six-character code will be used to number the TRA-731 caustic and acid storage tank rinsate samples. The first four characters, "731B," refer to the tank number (i.e., caustic storage tank TRA-731B). The next three characters refer to the sample number collected for each analysis (i.e., 001, 002). The last character refers to the particular class of analysis ("M" for metals). Hence, the first sample from tank TRA-731B will be labeled, "731B001M."

4.1.1.3 Field Sampling Logbooks. Field logbooks are legal documents that are the written record for all field data gathered, field observations, field equipment calibrations, samples collected for laboratory analysis, and sample custody. Logbooks are also maintained to ensure that field activities are properly documented as they relate to site safety meetings and that site work is conducted in accordance with the health and safety procedures. Field logbooks will be bound and will contain consecutively numbered pages. All entries to field logbooks will be made using permanent ink pens or markers. All mistakes made as entries will be amended by drawing a single line through the entry, initialed, and dated by the person making the correction. At a minimum, the following entries will be made to the field logbook: 
- Identification of all sampling team members

- $\quad$ References to field methods used to obtain samples, field data, etc.

- $\quad$ Location and description of each sampling point

- $\quad$ Types, numbers, and volumes of samples (when observable)

- Date of sample collection, time of sample collection, and sample identification

- Date and time of sample shipping or transfer of sample custody

- $\quad$ Observed weather conditions

- $\quad$ All field measurements

- $\quad$ Any deviations from the standard or expected procedure

- $\quad$ COC form numbers.

4.1.1.4 COC Record. The COC procedures will begin immediately after collection of the first sample. At the time of sample collection, the sampling team will ensure that the sample is logged on a COC form. All samples collected will then remain in the custody of a member of the sampling team until custody is transferred to the laboratory SC. Upon receipt at the laboratory, the SC will review sample labels and the COC form to ensure completeness and accuracy. If discrepancies are noted during this review, immediate corrective action will be sought with the sampling team member(s) identified on the $\mathrm{COC}$ as delivering the samples. If discrepancies cannot be corrected with the sample team members, the PM will be sought to correct sample labeling or COC discrepancies.

Pending successful corrective action, or when no corrective action is required, the laboratory SC will sign and date the COC form signifying acceptance of delivery and custody of the samples. The sampling team will retain a copy of the signed COC and will note the time of sample custody transfer in the field logbook. Sufficient copies of COCs will be made at the time of sample delivery to ensure that appropriate personnel have copies. The laboratory will maintain possession of the original copy of the COC until completion of sample analysis and will maintain one copy of the COC for the term of storage of data at the laboratory. Only at the time of disposal of laboratory data, or transfer to the Environmental Affairs Administrative Record, will a copy of the COC form be out of the laboratory's control. The original copy of the COC form will be returned to the project file maintained by the PM along with the final data package deliverable.

\subsubsection{Laboratory Records}

Laboratory records are required to document all activities involved in sample receipt, processing, analysis, and data reporting. The following sections describe the laboratory records that will be generated for this project. 
4.1.2.1 Sample Data. Sample data are records that contain the times that samples were analyzed to verify that they met holding times prescribed by the analytical methods. Sample data records should include information on the overall number of samples analyzed in a given day, location of sample analysis (i.e., instrument identification number), any deviations from analysis SOPs and/or methods, and time and date of analysis. Corrective action steps taken to rectify situations that did not conform to laboratory SOPs and/or analytical methods (including steps taken to seek additional sample material if required) should also be noted in these records.

4.1.2.2 Sample Management Records. Sample management records document sample receipt, handling and storage, and scheduling of analyses. The records verify that the COC and proper preservation were maintained, reflect any anomalies in the samples (such as receipt of damaged samples), note proper log-in of samples into the laboratory, and address procedures used to prioritize samples received to ensure that holding time requirements were met.

4.1.2.3 Test Methods. Unless analyses are performed exactly as prescribed in the analytical methods or laboratory SOPs, test methods describe how the laboratory carried out the analyses. Items to be documented include sample preparation and analysis, instrument standardization, detection and reporting limits, and test-specific QC criteria. Documentation demonstrating laboratory proficiency with each method used could also be included in this category.

4.1.2.4 QA/QC Reports. The QA/QC reports will include general QC records, such as initial demonstration of capability of individual analysts to conduct specific analyses, instrument calibration, routine monitoring of analytical performance (e.g., control charts), and calibration verification.

Project-specific information from the QA/QC checks such as blanks (e.g., field, reagent, and method), spikes (matrix and matrix spike duplicate), calibration check samples (e.g., zero check, span check, and mid-range check), replicates, and splits should be included in these reports to facilitate data quality analysis. Specific requirements for the reporting format and quantity and types of QA/QC monitoring will be specified in the analytical SOW to the laboratory.

\subsection{Document Control}

Document control consists of the clear identification of all project-specific documents in an orderly form, secure storage of all project information, and controlled distribution of all project information. Document control ensures controlled documents of all types related to the project will receive appropriate levels of review, comment, and revision, as necessary. It also ensures that all documents, which will ultimately affect project QA, are correct prior to their use.

The PM is responsible for properly maintaining active project files. Upon completion of the TRA-731 caustic and acid storage tank system post-decontamination characterization effort, the PM will transfer all hard-copy information and documentation developed from the project (including field logbooks, field and laboratory COC forms, laboratory reports and data, engineering calculations and drawings, final design reports, and all other technical reports related to the project) to TRA Projects for archiving, as appropriate. Copies of all analytical data and/or final reports will also be retained in the laboratory files, and at the discretion of the laboratory manager or QA officer, will be stored on computer disk and in hard-copy form for a minimum of five years from point of generation. Data will be made available for retrieval by authorized project staff from TRA Projects and the laboratory archives upon request. 


\section{SAMPLING PROCESS DESIGN}

Sample handling for the post-decontamination characterization effort at the TRA-731 caustic and acid storage tanks will require a series of specific procedures to ensure data are representative of the decontamination solutions following final rinsing of the tanks. The following sections outline the specific sampling process design for this effort.

\subsection{Sample Collection}

The TRA-731 caustic and acid storage tanks will be decontaminated using high-pressure steam. Decontamination activities will be conducted in such a way that all internal tank surfaces are contacted extensively by the high-pressure steam; the steam condensate (water) collected in the bottom of each tank will be the matrix sampled for closure certification of the TRA-731 caustic and acid storage tank system. Water is representative of potential leaching liquid that would contact the system under a tank system closure scenario. Screening-level samples will be used to ensure that the true mean concentration of contaminants of concern are below the established ALs.

When screening-level samples indicate that the contaminant of concern-specific ALs have been satisfied, each tank will undergo a final decontamination sequence (rinse). Samples for closure certification will be collected from the condensate (water) from each tank in the appropriate sample containers listed in Table 5-1. The samples from the final rinse of each of the storage tanks will be collected using a peristaltic pump. The peristaltic pump tubing will be located down the centerline of the bottom of each tank. At least two samples from each tank will be collected from the locations identified on Schematic P-CLOS-TRA-731-4 by pulling the tubing to the approximate location specified. Following rinsate sampling of a tank, the peristaltic pump will be completely evacuated of any remaining decontamination solution prior to commencing sampling of the next tank.

Table 5-1. Summary of sample collection, hold time, and preservation requirements for samples collected.

\begin{tabular}{|c|c|c|c|c|c|c|}
\hline Analysis & $\begin{array}{l}\text { Sample } \\
\text { Medium }\end{array}$ & $\begin{array}{c}\text { Sample } \\
\text { Volume } \\
(\mathrm{mL})\end{array}$ & $\begin{array}{c}\text { Number of } \\
\text { Samples per } \\
\text { Tank }\end{array}$ & $\begin{array}{c}\text { Container } \\
\text { Type }^{\mathrm{a}}\end{array}$ & Hold Time & Preservative \\
\hline $\begin{array}{l}\text { Total } \\
\text { metals }\end{array}$ & Water & 1000 & 2 & HDPE bottle & $\begin{array}{c}180 \mathrm{~d} \\
\text { except } \mathrm{Hg}(28 \mathrm{~d})\end{array}$ & $\mathrm{HNO} 3$ to $\mathrm{pH}<2$ \\
\hline
\end{tabular}

\subsubsection{Sample Transport}

After the appropriate pre-labeled sample containers have been filled and the $\mathrm{pH}$ verified, the samples will be placed in a shipping cooler containing sufficient blue ice to maintain the temperature of the container at approximately $4^{\circ} \mathrm{C}\left( \pm 3^{\circ} \mathrm{C}\right)$. The completed COC form, prepared by the sampling team member during sample collection, will be taped inside the cooler to document relinquishment of sample custody. Custody seals will then be taped to the shipping cooler to ensure the integrity of the COC between the INEEL and the analytical laboratory. 
Quality control samples include field blanks introduced at the appropriate point of the process. Field blanks are analyte-free water that is poured into a sample container at the sample collection site to check cross-contamination attributable to ambient site conditions, sample collection and shipment. Field blanks are often not collected during soil and waste sampling activities because the very low level of cross contamination detectable using field blanks would not affect a decision concerning data obtained from measurements on a concentrated waste. In the case of this sampling, as the material being sampled is the decontamination rinsate solution, data concerning cross-contamination may be useful for data interpretation.

\subsubsection{Sample Preservation}

Sample preservation is conducted to ensure that target analytes do not escape from field samples or become chemically attached to sample containers prior to analysis. Typical sample preservation activities include the addition of acids to ensure that metals remain in solution.

Sampling personnel shall inspect the individual samples to determine if each sample container has sufficient material to perform the requested analysis. The individual samples must be placed high-density polyethylene (HDPE) containers and preserved, as described in Table 5-1, prior to transport to the laboratory performing the analyses. Confirmation that the $\mathrm{pH}$ is $<2$ will be performed in the field using litmus paper. 


\section{SAMPLING PROCEDURES}

Sampling of the TRA-731 caustic and acid storage tank rinsates for HWMA/RCRA closure certification will be performed upon completion of tank decontamination efforts (high-pressure steam cleaning). The final rinsate samples (steam condensate) will be collected using a peristaltic pump. The peristaltic pump tubing will be located down the centerline of each tank and samples collected from each of the locations specified on Schematic P-CLOS-TRA-731-4. Once adequate volume is obtained and placed in the sample container, the tubing will be moved to the next specified sample location. The following is a conceptual overview of the sampling and analysis procedures to be performed as part of final rinsate analysis from the TRA-731 caustic and acid storage tank system. Sampling will follow the procedure:

- Decontaminate all tank interior surfaces using high-pressure steam.

- Collect screening-level samples of the steam condensate to ensure that contaminant of concern ALs have been satisfied.

- $\quad$ Based on analysis results, evaluate whether decontamination efforts have satisfied the performance standard (contaminant of concern-specific ALs satisfied) as stated in the HWMA/RCRA closure plan. If the performance standard is not satisfied, perform additional decontamination of the tank and repeat screening level analysis.

- $\quad$ Once screening-level samples indicate that the ALs have been satisfied, complete one additional decontamination cycle.

- Draw required sample volume from the bottom of each tank at the sample locations specified on Schematic P-CLOS-TRA-731-4 using a peristaltic pump and place sample in a prepreserved $1000 \mathrm{~mL}$ HDPE sample bottle.

- $\quad$ Prepare quality control samples (see below).

- $\quad$ Transport samples to laboratory for analysis.

- Receive laboratory analysis of sample.

- Obtain independent validation of data.

- $\quad$ Perform DQA on the data to test the statistical hypothesis stated in the DQOs.

- Dispose of spent decontamination solution, as appropriate, based on a completed hazardous waste determination.

Summaries of the samples to be collected during the sampling effort are summarized in Table 5-1. The table also provides an estimate of the number of anticipated samples, and the anticipated analyses to be requested for each sample. 
Quality control samples include field blanks introduced at the appropriate point of the sampling event. Field blanks are analyte-free water that is poured into a sample container at the sample collection site. Field blanks check cross-contamination during sample collection and shipment. Field blanks also provide information on contamination introduced by ambient site conditions. Field blanks are often not collected during waste sampling activities because the very low level of cross-contamination detectable using field blanks would not affect a decision concerning data obtained from measurements on a concentrated waste. However, in the case of this sampling, as the material being sampled is the decontamination rinsate, data concerning cross-contamination may be useful for data interpretation. Therefore, two field blanks will be collected during sampling unless all samples are collected in one day. If sampling is completed in one day, only one field blank will be collected. 


\section{ANALYTICAL METHODS}

To ensure that data of acceptable quality are obtained from the post-decontamination characterization of the rinsate solutions collected from the TRA-731 caustic and acid storage tanks, standard EPA laboratory methods will be used to obtain project laboratory data. The analytical methods and a description of each method that will be used to determine inorganic constituents are presented in Table 7-1.

Table 7-1. Analytical method source documents and method summaries.

\begin{tabular}{lll}
\hline Method & \multicolumn{1}{c}{ Description } & \multicolumn{1}{c}{ Source Document } \\
\hline \multirow{2}{*}{$3010 \mathrm{~A}$} & Acid digestion of aqueous samples and & Test Methods for Evaluating Solid \\
& extracts for total metals for analysis by & Waste, Physical/Chemical Methods, \\
& FLAA or ICP spectroscopy & SW-846 (EPA 1986) \\
6010B & Inductively coupled plasma-atomic emission & Test Methods for Evaluating Solid \\
& spectroscopy & Waste, Physical/Chemical Methods, \\
& & SW-846 (EPA 1986) \\
7421 & Lead Analysis by Atomic Absorption & Test Methods for Evaluating Solid \\
& (Furnace Technique) & Waste, Physical/Chemical Methods, \\
& & SW-846 (EPA 1986) \\
$7470 A$ & Analysis of mercury by automated pulse & Test Methods for Evaluating Solid \\
& flow cold vapor atomic absorption & Waste, Physical/Chemical Methods, \\
& spectroscopy & SW-846 (EPA 1986) \\
& &
\end{tabular}




\section{INSTRUMENT CALIBRATION PROCEDURES}

To ensure that sampling and analysis activities obtain the most accurate and precise information possible, field equipment and laboratory instrumentation must be calibrated according to both manufacturer specifications and the appropriate analytical method specifications.

\subsection{Laboratory Instrument Calibration}

Laboratory instrumentation will be calibrated in accordance with each of the specified analytical methods (Table 7-1). The laboratory QA plan shall include requirements for calibrations when specifications are not listed in analytical methods. Calibrations that are typically not called out in analytical methods include those for ancillary laboratory equipment (e.g., analytical balances, pipettes, and $\mathrm{pH}$ meters) and verification of reference standards used for calibration and standard preparation. Laboratory documentation will include calibration techniques and sequential calibration actions, performance tolerances provided by the specific analytical method, and calibration dates and frequency. In addition, records for all laboratory-prepared standards will be maintained and provided with each data deliverable. Standard reference materials used to perform calibration checks associated with inorganic target analytes will be prepared using an independent source for the standard materials from that used for preparation of the calibration standards. The results of these calibration checks will be reported with each data deliverable.

All analytical methods prescribed in Table 7-1 have specifications for equipment checks and instrument calibrations. The laboratory will comply with all method-specific calibration requirements for all requested parameters. If a failure of instrument calibration or equipment is detected, the instrument will be recalibrated, and all affected samples will be analyzed using an acceptable calibration.

\subsection{Field Equipment Calibration/Setup}

The required presampling inspections will evaluate all pumps and sampling equipment to ensure that they are functioning properly prior to sample collection. Corrective actions for the repair or maintenance of sampling equipment will be immediate and will be confirmed by the PM prior to sample collection.

\subsection{Preventative Maintenance Procedures and Frequency}

Field equipment will be managed by a calibration program compliant with MCP-2391, "Calibration Program," requirements (INEEL 2001b). All laboratory equipment will be maintained to a level such that each piece of equipment and each laboratory instrument can meet method-specific QA/QC tolerances. Maintenance will be performed, under the supervision of qualified personnel, on all laboratory instrumentation in accordance with the manufacturer's specifications, laboratory QAP and/or SOPs.

Preventive maintenance of field equipment will be conducted in accordance with appropriate facility SOPs. It is a requirement of the most recent EPA Guidance for Quality Assurance Project Plans (EPA 1998) that the performance of all activities, not governed by specific analytical procedures, be completed under approved SOPs. Therefore, if SOPs governing the inspection and maintenance of sampling equipment do not presently exist, they must be developed to ensure that sampling activities are conducted using equipment that is performing within manufacturer or design specifications.

Equipment used by TRA ESH\&Q oversight personnel will be evaluated, maintained, and operated within the manufacturers' specifications for each type of field or monitoring equipment. 


\section{DATA VALIDATION AND REPORTING}

To ensure that all data are acceptable, and that data end users receive information in a form that is usable, a series of evaluations and data reduction steps must occur. Data generated by the laboratory and in the field are only the first step in evaluating conditions at any project site.

\subsection{Data Reduction}

Data reduction is the process of converting raw data or instrument data into a usable form for evaluation by project personnel. Reduction of environmental data will occur at the laboratory. The data reduction activities performed at the laboratory convert the data into a form that is used for interpretive purposes for environmental risk assessment and verification of closure design.

Laboratory data reduction involves converting the outputs of the analytical instruments into sample and QC results. Laboratory reduction will be performed as defined in the analytical method. Laboratory deliverables include raw and reduced data. This form of laboratory deliverable will ensure complete documentation of all aspects of laboratory analysis, allow for an independent verification of reported results, provide a form of data that is technically and legally defensible, and ensure that data end users can be completely confident in the results.

Further data reduction may be necessary for use at the project level. When this is necessary, project management will determine the final data uses and parameter needs and provide data sets in the form that project personnel require to complete their tasks. Examples of additional data reduction tasks include unit conversions.

Scientists and regulators within the EPA, DOE-HQ, DOE-ID, and IDEQ may also review the data to ensure compliance with HWMA/RCRA closure requirements. Individual regulators will make requests of the PM for any data sets required to evaluate the post-decontamination characterization effort. Project management will provide requested information to regulators in the most usable form possible.

\subsection{Data Validation}

Analytical data validation is the comparison of analytical results versus the requirements established by the analytical method. Validation involves evaluation of all sample-specific information generated from sample collection to receipt of the final data package by the PM. Data validation is used to determine if the analytical data are technically and legally defensible and reliable. The SW-846 QC guidelines will be used to validate the data. Data validation is a portion of the DQA process that is used to determine the data meet the project DQOs. Additional steps of the DQA process involve data plotting, testing for outlying data points, and statistical hypothesis testing relative to the null and alternative hypotheses stated in the DQOs.

The final product of the validation process is the validation report. The validation report communicates the quality and usability of the data to the decision-makers. The validation report will contain an itemized discussion of the validation process and results. Copies of the data forms, annotated for qualification as discussed in the validation report, will be attached to the report. The additional steps of the DQA process stated above are not documented in the validation report. The DQA process is completed following receipt and evaluation of all analysis batch-specific validation reports. Because the statistical hypotheses will be tested using the calculated mean concentration of the contaminants of concern in each of the TRA-731 tanks separately, DQA can be completed once all data for an individual tank have been received. 


\section{$9.3 \quad$ Reporting}

The laboratory may use its standard report forms when assembling the final data package documentation. However, each deliverable must conform to the Tier 1 deliverable as defined in ER-SOW-156 (INEL 1995).

The ER-SOW-156 Tier 1 data deliverables include all pertinent raw data, extraction notes, standard preparation, instrument print-outs, standard reference material certificates, etc. Use of these

environmental restoration (ER) documents is to establish technical and reporting standards only, and does not imply the involvement of the ER program in the TRA-731 caustic and acid storage tank system closure project. The ER-SOWs, prepared by the INEEL Sample Management Office (SMO), have become the standard means by which analytical data deliverable requirements are defined by INEEL projects to both the INEEL laboratories and commercial laboratories used by the INEEL. 


\section{INTERNAL QUALITY CONTROL CHECKS AND FREQUENCY}

To adequately assess the quality of sampling techniques, the cleanliness of sampling and shipping methods, and laboratory accuracy and precision, field QA/QC samples are submitted with rinsate samples at the time of custody transfer to the laboratory. The following sections outline specific QC checks that will occur for this project.

\subsection{Laboratory Quality Control}

Compliance with laboratory QA/QC procedures and strict adherence to analytical method tolerances will be critical to obtaining high-quality laboratory data. Each analysis conducted for the TRA-731 post-decontamination HWMA/RCRA closure certification will strictly adhere to all QA/QC procedures, QA/QC control limits, and method-specific corrective actions.

\subsection{Field Quality Control}

Field quality control requirements for field blanks are addressed in Section 5.1.1. 


\section{PERFORMANCE AND SYSTEMS AUDITS AND FREQUENCY}

It is not a requirement of this $\mathrm{QAPjP}$ that a formal audit of the analytical laboratory be performed prior to commencing with the TRA-731 caustic and acid storage tank system closure certification effort. Using a laboratory that is on the INEEL-approved suppliers list ensures that an appropriate onsite audit has been conducted (or recognized) by the INEEL SMO within the last 18 months. If deviations from the procedures outlined in this QAPjP are suspected during analysis, the PM should review the laboratory procedures that were used to obtain project data.

\subsection{Corrective Action}

Corrective action procedures are implemented whenever sampling, field monitoring, or laboratory analysis results do not meet the required QA/QC standards. The types of corrective action applicable to environmental analysis are laboratory corrective action(s) and field corrective action(s).

\subsubsection{Laboratory Corrective Action}

The laboratory manager, laboratory QA officer, laboratory analysts, the PM, and sampling and data quality personnel will be responsible for ensuring that all laboratory QA/QC procedures are followed. Situations requiring corrective action, and the type of correction required, will be as stated in the analytical method or the laboratory SOW. The laboratory will utilize internal QAPs and SOPs to complete all corrective actions identified both internally and externally. Completion of corrective actions will require notification of the PM or the sampling and data quality personnel of any laboratory situation that may impact the usability of the data. If notified of a laboratory nonconformance for which the laboratory seeks the project's required corrective action, sampling and data quality personnel will:

- $\quad$ Notify the PM of the situation

- Devise a reasonable corrective action in conjunction with the laboratory staff and the PM

- $\quad$ Request, formally, that the laboratory implement the corrective action.

All sampling and data quality personnel and the laboratory QA officer will be responsible for monitoring the effectiveness of all corrective actions. The sampling and data quality personnel will report directly to the PM and INEEL management and operations contractor regarding problems or deviations observed, corrective actions proposed, and the effectiveness of ongoing corrective actions.

\subsubsection{Field Corrective Action}

The FTL and PM are responsible for ensuring all field procedures are completely followed and that field personnel are adequately trained. The FTL and the PM must document situations that may impair the usability of the samples and/or data in the field logbook. The FTL will note any deviations from the standard procedures for sample collection, COC, sample transport, or any other monitoring that occurs. The FTL will also be responsible for coordinating all activities relating to the use of field monitoring equipment, such as dosimeters and IH equipment. The TRA ESH\&Q oversight personnel will provide any notations to the logbook, which document noncompliant measurements taken during field sampling. Ultimately, the PM or the FTL (at the discretion of the PM) will be responsible for communicating field corrective action procedures, documenting all deviations from procedure, and ensuring that immediate corrective actions are applied to field activities. 


\section{REFERENCES}

40 CFR 265, "Interim Status Standards for Owners and Operators of Hazardous Waste Treatment, Storage, and Disposal Facilities," Code of Federal Regulations, Office of the Federal Register, July 2000 .

DOE-ID, 2001, HWMA/RCRA Tank System Closure Plan for the TRA-731B and C Caustic and the TRA-731D and E Acid Storage Tank System, 1997 Notice of Violation Consent Order, DOE/ID-10898, Revision 0, September 2001.

EPA, 1986, Test Methods for Evaluating Solid Waste, Physical/Chemical Methods, Office of Solid Waste and Emergency Response, SW-846, ${ }^{\text {rd }}$ Edition, Revised, 1986.

EPA, 1992, Guidance for Data Usability in Risk Assessment (Part A), Office of Emergency and Remedial Response, Washington, D.C., 9285.7-09A, 1982.

EPA, 1994, EPA Guidance for the Data Quality Objectives Process, EPA QA/G-4, EPA/600/R-96/055, September 1994.

EPA, 1998, EPA Guidance for Quality Assurance Project Plans, EPA QA/G-5, EPA/600/R-98/018, February 1998.

IDAPA 58.01.05.009, "Rules and Standards for Hazardous Waste," Idaho Administrative Procedures Act, Idaho Department of Environmental Quality Rules, April 15, 2000.

INEEL, 1999, "Sample Management," Companywide Manual 18-Closure Management, MCP-2864, Revision 3, September 3, 1999.

INEEL, 2000, "Logbooks for ER and D\&D\&D Projects," Companywide Manual 18-Closure Management, MCP-231, Revision 4, July 11, 2000.

INEEL, 2001a, Field Sampling Plan for HWMA/RCRA Closure Certification of the TRA-731 Caustic and Acid Storage Tank System, 1997 Notice of Violation Consent Order, INEEL/EXT-01-01281, Revision 0, October 2001.

INEEL, 2001b, "Calibration Program," Companywide Manual 13B-Quality and Requirements Management Procedures, MCP-2391, February 26, 2001.

INEL, 1995, INEL Sample Management Office Statement of Work for Inorganic and Miscellaneous Classical Analyses, ER-SOW-156, May 1995.

Kachigan, Sam K., 1982, Multivariate Statistical Analysis, A Conceptual Introduction, New York, New York, Radius Press, 1982.

Pisarski, D. J., IDEQ, to D. N. Rasch, DOE-ID, May 4, 1999, Enclosure: "Signed Consent Order to Resolve the August 25, 1997, Notice of Violation." 